\title{
The Language of Online Activism A Case from Kuwait
}

\author{
Jon Nordenson
}

$$
\text { ما أبي أعلق عالصورة .. بس لو تغيرون الصورة والموضوع .. وايد أحسن }
$$

I do not wish to comment on the picture .. But if you change the picture and the subject .. much better

"[User 1]", debate on blog, July 29th, 2006

$$
\begin{aligned}
& \text { إذا لميهز خطاب البراك "ضمير" السلطة في شيء فلن لن [sic] يحركه بعد ذلك أي خطاب }
\end{aligned}
$$

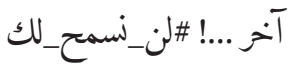

If al-Barrāk's speech doesn't shake the "consciousness" of the regime in any way, then no other speech will do so later

“@[User 2]", Twitter, 15.10.2012

The quotes presented above are taken from the online debates of two different, but related, political movements in Kuwait. The first is from the liberal dominated 2006 campaign to change the electoral law, and the second is from the ongoing oppositional movement seeking extensive political reform, ${ }^{2}$ dominated by Islamist and tribal protagonists. Judging by the examples given above, a difference between the two can also be found in terms of language preferences: the protagonists in the 2006 campaign apparently preferred Kuwaiti Arabic (KA), and those in 2012 Standard Arabic (SA). Why is this so?

1 All examples used have been anonymized. Usernames and identities are not relevant to the material. Moreover, one should always be cautious when relaying online statements, even when, as in this case, all statements have been made in public, through open channels. Finally, this is particularly important given the topics discussed in the examples used, and the Kuwaiti regime's increasing willingness over the past few years to persecute Kuwaitis for any critical statements made online. All examples in their original form have been kept by the author.

2 This movement began in 2009. While it has been markedly less active following the Kuwaiti Government's repression of public protests in the autumn of 2012, some of the groups involved are still active, hence the term "ongoing." 
This chapter seeks to answer this question through an empirical study of the written language employed online by activists engaged in the two campaigns. The findings are compared to random samples of Twitter-usage in the country, in order to establish whether or not the language employed by political activists differ from that of the average Kuwaiti Twitter user. The findings suggest a tendency towards KA features among the liberal activists in 2006, a tendency towards SA features among the oppositional activists currently active, and an equal distribution of KA and SA features among the "average" Twitter user. Before the findings are presented in detail, however, a look at the relevant context and the background for this study is in place.

First of all, the sheer volume of written material published online dictates academic attention. Globally, more than 320 million people use Twitter monthly, in more than 35 languages. ${ }^{3}$ As for Facebook, the site had more than 1 billion daily users as of November 2015, and 1,55 billion monthly users. ${ }^{4}$ About one billion unique users visit YouTube every month, and hundreds of millions of hours of video are watched every day. ${ }^{5}$ On Wordpress, more than $5^{6}$ million new posts and 52,5 million comments are published every month. ${ }^{6}$ In short, an enormous production takes place continuously online, the likes of which has never before been seen. Although internet access and usage varies greatly between Arab states, the online production in the region is also tremendous. According to the Mohammed Bin Rashid School of Government (formerly the Dubai School of Governance), the internet penetration rate in the Arab world reached $36 \%$ in 2014, as compared to a global average of $40 \%$ (Mourtada and Salem 2014:1)..$^{7}$ Similarly, social media usage in the region is on the rise, and from 2013 to 2014, the number of Twitter and Facebook users increased with $54 \%$ and 49\%, respectively (Mourtada, Salem and Shaer 2014:6). For those interested in the use and development of the Arabic language, this widespread internet usage raises a number of important questions, including whether or not the increase in the production of written material affects the language used.

3 As of November 2015. Twitter: "about, company". URL: https://about.twitter.com/company. Accessed: November 17, 2015 .

4 As of November 2015. Facebook: "Company info". uRL: http://newsroom.fb.com/company -info. Accessed: November 17, 2015.

5 As of November 2015. YouTube: "Statistikk". URL: https://www.youtube.com/yt/press/no/statistics.html. Accessed: November 17, 2015.

6 As of November 2015. Wordpress: "activity". URL: https://wordpress.com/activity. Accessed: November 17, 2015 .

7 We should keep in mind that figures concerning internet access is difficult to establish with any certainty. However, there is no doubt that access and usage in the region has increased markedly over the past few years, and that internet usage now is a part of everyday life for a substantial part of the population. 
Several previous studies of language use online in the Arab world have looked into the use of Arabic written with Latin letters, often referred to as Arabeasy (Aboelezz 2009, Palfreyman and Khalil 2003, Peel 2004, Warschauer, Said and Zohry 2002). Such studies have found that the language rendered through Latin letters usually is a colloquial variety rather than SA. Similarly, Allman argued that the preliminary evidence (on online communication) "suggests that the internet provides a venue for two socio-linguistic occurrences, the translation of spoken vernacular into writing and the mutual acceptability of colloquial usage online", in addition to code-switching between English and Arabic (Allmann 2009:67). In her view, features of online communication should be seen in connection with the instantaneous nature of many of the platforms used, as "synchronous modes tend to be more speech-like (...)" (Ibid., p. 65). In her 2012 study of Egyptian blogs, Ramsay looked into the language employed by the top five ranked Arabic language blogs in the country. Interestingly, all bloggers used Arabic script "whatever code they express themselves in" (Ramsay 2012:54). She found that "the bloggers (...) select their code of representation and adjust it to the aim of the blog and the desired audience" (Ibid., p. 83). More specifically, what she termed activist bloggers tended towards Egyptian Colloquial Arabic (ECA), and educational bloggers tended towards SA. As we shall see, the material presented here supports these findings, as the expected audience seems to be a decisive factor in terms of language choices made.

Arabic internet users make choices concerning script (Arabic/Latin), language (Arabic, English, other), and variety (sA or colloquial Arabic), and frequently mix and/or switch between these. As pointed out by Mark Sebba: "written language mixing remains relatively unexplored and under-researched (...)" (Sebba 2012:1). As for written Arabic online, Ramsay states that "choice of language variety and linguistic style in blogs, electronic communication and throughout cyberspace remains a vast and independent field in Arabic studies which has yet to be explored" (Ibid., p. 83), and that "establishing valid theories and efficient methods (...) is a substantial task yet to be carried out" (Ibid., p. 50). Similarly, Allmann argued that "Arabic language use online is an understudied case" (Allmann 2009:73). Thus, while most studies seem to agree that the use of written colloquial is a dominant future of online communication and that this may or may not be done using Latin script, it is still too early to draw any definitive conclusions. Moreover, Androutsopoulos argues that researchers need to "demythologize" language use in computer mediated communication (CMC), as early research often used terms such as netspeak that ascribe common features to the language used on particular platforms, such as e-mails (Androutsopoulos 2006:420). In his view, it is empirically questionable whether 
a "language of e-mail" exists. Instead, he argued that "[r]ather than identifying e-mail, chat or weblogs as new genres per se [original italic], the question is how these communications technologies are locally appropriated to enact a variety of discourse genres" (Ibid., p. 421). Similarly, Orgad argued that "[i] thas become clear that the separation between the online and offline cannot be sustained. Researchers have consistently argued for the need to frame the online both in its own right and in relation to other contexts and realities" (Orgad 2008:37). As such, we should not reduce language use online to a simple function of technology.

This study aims to address some of the issues raised above. Whereas previous studies often have focused on particular writers and informants, this study aims to get the "bigger picture", so to speak, by selecting random samples from the cases in question. As the material gathered is quite extensive, coding of particular features of the language variety employed is used rather than describing the features of the text following a close reading of the material. Recognizing that it is impossible to study language use online per se, the study is focused on a particular activity mediated through online platforms, namely political activism. While most research on language use online so far has focused on Egypt, the cases here are from Kuwait. I do not aim to provide an exhaustive description of the code employed, but rather to establish which code is used, which script is used, and to identify features of KA, SA, or combinations of the two. Finally, the findings are discussed within the relevant contexts (both online and offline), so as to avoid ascribing agency to the internet itself.

\section{Cases, Material, and Analysis}

The starting point for this study was the observation by the author that the language employed online by activists in Kuwait seemed to be drifting from what I would describe as an informal mix of KA and SA in the mid-2ooos, towards purer SA during the past few years. The observation from the mid200os stems from my previous study of a 2006 youth-led campaign to change the electoral districts in Kuwait, known as the Orange Movement (ом), in Arabic referred to as either al-Haraka al-Burtuqāliyya or Nabīhä Khamsa (we want five). ${ }^{8}$ The group demanded five electoral districts - hence the name

8 The name of the group in SA should of course be Nabghīhā Khamsa. However, in Kuwaiti dialect, the ghayn is omitted in this particular verb. 
in Arabic - arguing that this would hinder alleged Government efforts to manipulate elections for the national assembly. The group was born online, and blogs were the preferred platform of activists at the time. Using the 'comments' function on the blogs involved, activists discussed their aims, their arguments, and how to proceed with their campaign. The movement was dominated by hadar activists (Nordenson 2010), that is, the part of the population historically living in Kuwait city (in English often referred to as city-dwellers), which also has been the dominant group in socio-economic and political terms. However, several activists of tribal background were also involved, referred to as the badu part of the population, which in turn has been politically and economically marginalized (Al-Nakib 2014, Ghabra 1997).

Recently, I have been studying a youth-led campaign for political reform in the country, which also makes extensive use of online platforms, and, most of all, Twitter. While the campaign consists of several groups, it can meaningfully be described as one campaign, since there is a general agreement on the main aims: a more democratic Kuwait through reform of the electoral law and the constitution, including instituting a full parliamentary system. The groups and activists have suffered tough reactions from the Government over the past few years, and only a few remain active today. Although the groups involved primarily relied on offline mobilization to effect change, they were highly active online. Twitter was used to argue for their cause, to mobilize followers, and to discuss the issues at hand. Through numerous debates organized around particular hashtags, thousands of participants discussed questions such as why one should implement a parliamentary system, how the constitution should be reformed, and the content of speeches given at rallies. These debates were often initiated by others than the groups active in the campaign, but were clearly based within the oppositional camp. Participants included not only activists, but members of Parliament, journalists, political analysts, members of the royal family, and "regular" Kuwaitis. While there are liberal, hadar activists taking part in the campaign, it has been dominated by tribal and Islamist activists and politicians. ${ }^{9}$

Based on the differences observed in the language employed through the two campaigns, this study seeks to answer the following questions:

- What are the characteristics of the language used online by young activists in Kuwait, in terms of the local vernacular as opposed to SA?

9 See for instance: Foreign Policy, October 23rd 2012, "Kuwait's balancing act". URL: http:// foreignpolicy.com/2012/10/23/kuwaits-balancing-act. Accessed: November 17, 2015. 
- Are there any differences to be identified in the language practices of liberal and religious/tribal activists?

- If any differences are observed, what may be the reasons behind these?

The questions are answered through an analysis of material consisting of random samples from the activities of both campaigns. When the om was active in the spring and summer of 2006, Twitter did not exist, and blogs were the preferred platform. One blog in particular can be said to have been the main platform of the movement (called sāhat al-Ṣafät, after the central square in Kuwait with the same name), and during the campaign, no less than 65 blog posts and more than 6500 comments were published on the site. ${ }^{10}$ I have randomly selected 20 comments from three of the largest debates as the sample from this campaign. ${ }^{11}$ As for the latter campaign, I have identified 27 Twitter debates on oppositional issues organized around hashtags that took place between April 2012 and January 2013, encompassing more than 65 ooo tweets. I have randomly selected 50 tweets from three of the largest debates I have identified. ${ }^{12}$ Importantly, two of these debates were in conflict with one another, as they were concerned with whether or not one should participate in an oppositional demonstration in August 2012. Those intending to participate used one hashtag, and those who did not intend to participate used another. I have included both, so that what presumably are both oppositional and pro-Government Twitter-users are included.

Clearly, the two platforms are not directly comparable in the sense that they have different technical possibilities and limitations. However, if we are to compare activist debates online in 2006 and 2012, there is no alternative to comparing different platforms, and as such, it is a comparison of the online work

10 The blog is still online at http://kuwaitjunior.blogspot.no. Last Accessed: January 2oth 2015 .

11 In all 6o comments. The blog posts were as follows: May 3rd 2006: للشارع نتزل .. حضورك مهم 108 comments.

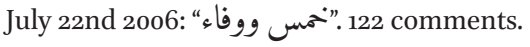

12 Tweets are shorter than most comments on a blog - Twitter does not allow for messages over 140 characters - and therefore the Twitter samples are larger than those taken from the blog. In all they include 150 tweets. It should be noted that not all tweets that may have been written using the hashtags in question necessarily are included, as tweets may have been written after I harvested the sample. The debates included are as follows: August 28th

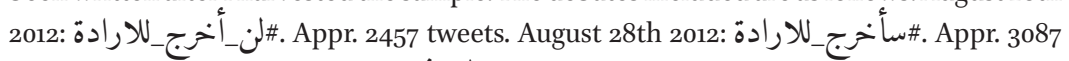

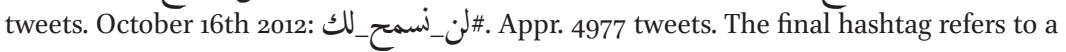
speech given by oppositional politician Musallam al-Barrāk. 
of activists in the country in 2006 and in 2012/2013. Finally, I have also included random samples of Twitter activity in Kuwait, harvested based on geographical location..$^{13}$ These are used to establish whether or not the language in political discussions is markedly different from language used for other purposes, or if the language on Twitter in itself is markedly different from that employed earlier on the blog. I only included tweets written in Arabic (be it with Arabic letters or Latin letters), containing a minimum of five words. I excluded tweets that only consist of a Quranic quote, as this hardly is informative of the language choices made by the protagonist in question.

All entries in all samples have been coded according to certain criteria. The intention was to provide a more transparent analysis than if I were to characterize the text as KA, SA, or a mix based on my own reading, in addition to solving the problem caused by the extent of the material. In each entry, I have looked for specific features, or markers, which have been coded as "Kuwaiti", "fuṣhā", or "both". These included negation, interrogatives, demonstrative pronouns, relative pronoun, adverbs of time, and some particular Kuwaiti expressions.

The features selected for coding were based on which features I expected to find most frequently. I did not include all possible variants of, for instance, negation markers, but rather included the SA and KA variants of those I assumed to be most often employed. The KA variants of these features are based on several sources on the Kuwaiti dialect (Al-Qenaie 2011, Holes 1984, Holes 1990, Holes 2011, Qafisheh 1997). ${ }^{14}$ Naturally, one entry may contain more than one feature, of one or more variety. Thus, one entry may contain both fuṣhā and Kuwaiti negations, fușhā interrogatives, and Kuwaiti relative pronouns, and will be coded as such. ${ }^{15}$

13 These samples have been harvested based on geographical location, that is, specific coordinates that include Kuwait city and the suburbs. This has been done through an application developed by the Department of Informatics at the University of Oslo, and I am extremely grateful to Morten Erlandsen for his continued help and support in this regard. 50 tweets from each sample have been included, 150 tweets in total. The samples are as follows: Sample 1, taken on May 13th 2014, at 11:42 am, and includes 706 tweets. Sample 2, taken on September 22nd 2014, at 1:00 pm, and includes 774 tweets. Sample 3, taken on October 23rd 2014, at 11:00 am, and includes 419 tweets.

14 In addition, I am forever indebted to my good friend Muhammad al-Yūsufī for help in establishing and correcting the relevant markers.

15 There are some problematic aspects to this approach. For one thing, the sampling is challenging. The possibility of anonymity provided online makes it difficult if not impossible to provide accurate samples, as it is not possible to determine how many different people actually took part in the debates, if they were situated in Kuwait, and if they were Kuwaitis. Moreover, some SA features are widely used also in the Kuwaiti vernacular, and may be 


\section{Kuwait, Activism, and the Internet}

Kuwait is not a democracy. The ruling al-Ṣabāh family dominates politics in the country, the Amir appoints the Prime Minister, who in turn appoints the cabinet. Important positions such as Prime Minister, defense minister and interior minister, are reserved for members of the royal family (Herb 1999, Salem 2008). However, the country has an elected assembly which often has been eager to make use of the powers vested in it. The constitution is somewhat ambiguous, in that it declares Kuwait a democratic country, but at the same time stipulates that much power remains with the royal family. The unresolved question of power sharing characterizes politics in the country, and oppositional forces have sought democratic reform since independence. The room for oppositional politics has been shifting, and the regime has on two occasions dissolved the national assembly for extended periods of time. Throughout the years, the regime has allied itself with various parts of society to face off the opposition, including the Shia population, Islamists, and the tribal population. In 2006, the Orange Movement was largely allowed to operate freely. The campaign succeeded in their goal, and even met with the Amir afterwards in an apparent sign of appeasement. The current oppositional campaign started in 2009, and although their goal of removing the former Prime Minister was realized, they have increasingly been met with harsh measures from the regime. Thus, while the 2006 campaign was able to conclude its work peacefully, this has not been the case over the past few years.

The 2006 campaign represented the breakthrough of youth-led campaigns in Kuwait, and of the internet as a tool for activists and a site for political deliberations. Internet was introduced in Kuwait following the Iraqi occupation, and the Government actively sought to provide access to its citizens. As of 2014, the International Telecommunications Union (ITU) estimates that more than $78 \%$ of people in Kuwait used the internet. ${ }^{16}$ This is an increase from $28 \%$ in 2006 . It

difficult to classify. While this happened surprisingly seldom, there were some dubious instances. In these cases, I have relied on the rest of the message in order to interpret the feature in question. Some of the entries from the random Twitter sample have been difficult to interpret, due to a lack of both context and any established practice as to the spelling of several words in KA. Finally, this approach clearly does not provide the whole picture on the language employed, concerning, for instance, the spelling of KA, how and when KA and SA are mixed, and so on. These reservations should be kept in mind when reading the analysis and my conclusions.

16 The International Telecommunications Union, statistics, "Percentage of Individuals using the internet”. Available online: http://www.itu.int/en/ITU-D/Statistics/Pages/stat/default .aspx. Accessed: November 17, 2015 . 
is unclear, however, if this number refers to Kuwaiti citizens, or to people living in the country. Kuwait has a substantial amount of foreign workers, as well as a large, stateless population known as Bidūn (meaning "without," that is, those without citizenship). There is every reason to believe that the number of internet users is higher among Kuwaiti citizens than within the total population of the country. In terms of internet usage, social media are popular in Kuwait, and in particular Twitter. In fact, the country has the highest number of Twitter users per capita in the world (Mocanu et al. 2013). Influential figures in Kuwaiti society are highly active on the platform, and media in the country routinely refer to debates that take place. The Government, for its part, seems to take Twitter very seriously, and has increasingly persecuted activists for utterances made on the platform, even revoking citizenships. ${ }^{17}$

\section{The Findings}

The markers used in the analysis were selected based on what I assumed would appear quite frequently. However, many entries in all samples contained none or only a few of the markers used ${ }^{18}$ - an obvious problem for my analysis. The samples from the political debates on the blog contain substantially more markers than the other samples, and negation is by far the marker that most frequently occurs. In fact, negation is the only marker that is found somewhat

17 See for instance al-Jazeera, January 8th 2013, "Kuwaiti jailed for insulting emir on Twitter". URL: http://www.aljazeera.com/news/middleeast/2013/01/2013189218755379.html. See also al-Arabiyya, September 29th 2014, "Kuwait revokes citizenship of opposition figure, 17 others”. URL: http://english.alarabiya.net/en/News/middle-east/2014/og/29/Kuwait -revokes-citizenship-of-opposition-figure-17-others-.html. Accessed: November 17, 2015. Distribution of the markers in the various samples were as follows:

\begin{tabular}{lccc}
\hline & $\begin{array}{c}\text { Blog political } \\
\text { debates (\%) }\end{array}$ & $\begin{array}{c}\text { Twitter random } \\
\text { samples (\%) }\end{array}$ & $\begin{array}{c}\text { Twitter political } \\
\text { debates (\%) }\end{array}$ \\
\hline Negation & $63,5^{\circ}$ & 46 & 41,50 \\
Interrogatives & 35 & 13 & 9,50 \\
Demonstrative pronoun & 18 & 15 & 12 \\
Relative pronoun & $26,5^{\circ}$ & 13 & 9,50 \\
Adverbs of time & $6,5^{\circ}$ & 7 & 6 \\
Kuwaiti expressions & 25 & 4 & 6 \\
\hline
\end{tabular}


regularly, that is, in about half of the entries. However, although few entries contain many markers, the distribution of those markers that are found is quite evenly spread out. In other words, if we look at whether or not entries contain at least one marker as opposed to no marker at all, the picture changes. More than half of the entries from the sample of political debates on Twitter, and more than two thirds of the entries in the blog samples and the random Twitter samples, contain at least one marker. ${ }^{19}$

Still, as some entries only contain one marker, there clearly is a risk that single words may affect the analysis in a disproportionate manner. On the other hand, some of the tweets contain very few words - in some instances only five. It would be highly surprising if these short messages should contain many markers, but they are nevertheless part of the online, written production that takes place. Thus, we need to integrate these in our analysis regardless of the number of words used. In this regard, I believe the design applied here has proved to be adequate. Furthermore, if we are to make use of random sampling and larger data sets, as proposed here, a close reading of the entire material is hardly a realistic option. As a result, the only findings that will be used are those based on the distribution of negations, and on all markers seen together.

For negation, the coding of the material provided the results shown in figure 11.1.

The samples from the blog quite clearly tend towards a preference for KA (red), whereas the samples from the political Twitter debates tend towards SA (bold types): ${ }^{20}$

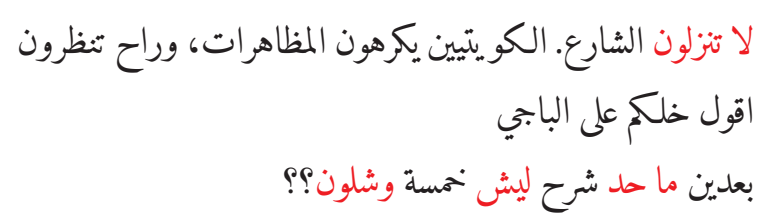

Do not take it to the streets. Kuwaitis hate demonstrations, and you will be harmed. I say remain as you were. And another thing, no one has explained why five, and where did it come from?

"[User 3]", May 4th 2006

19 In the samples from the political debates on the blog, $78 \%$ of all entries contained at least one marker. The corresponding figure for the political debates on Twitter and the random Twitter samples were $56 \%$ and $69,5 \%$, respectively.

20 In this and all following examples, SA variants of the features I have coded are marked in bold, and KA variants are red. 


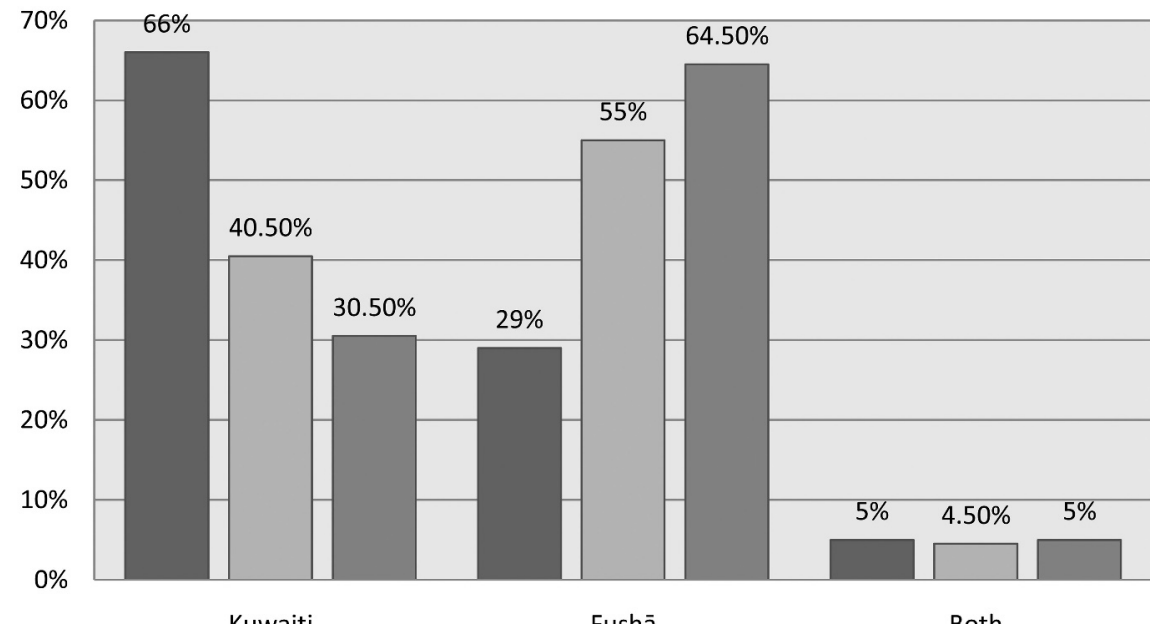

Blog political debates $\quad \square$ Twitter random samples $\quad \square$ Twitter political debates

FIGURE 11.1 Negation in entries with negation, all samples ${ }^{21}$

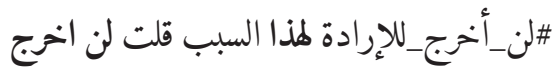

For this reason, I said I will not go out (to participate in a demonstration against the Government)

The user “@[User 4]" on August 27th 2012

While most of the tweets contained quite straight forward messages as the one given above, there were also quite a few rather lofty and passionate messages, which - perhaps - may have affected style, as in the following example:

$$
\text { الوطن ليس مكانا على الأرض فإنه فكرة في الذهن \#سأخرج_للإرادة }
$$

The homeland is not a place on the earth but an idea in the mind “@[User 5]" on August 26th 2012

The random Twitter samples also lean towards SA, as in the following example:

$$
\text { لن تكبر دون أن نتألم، ولن نتعلم دون أن تخطي، ولن تنجح دون أن تفشل، هكذا هي الحياة }
$$

21 Importantly, the figure is based on the distribution of varieties of negation within those entries that actually contains negation. 


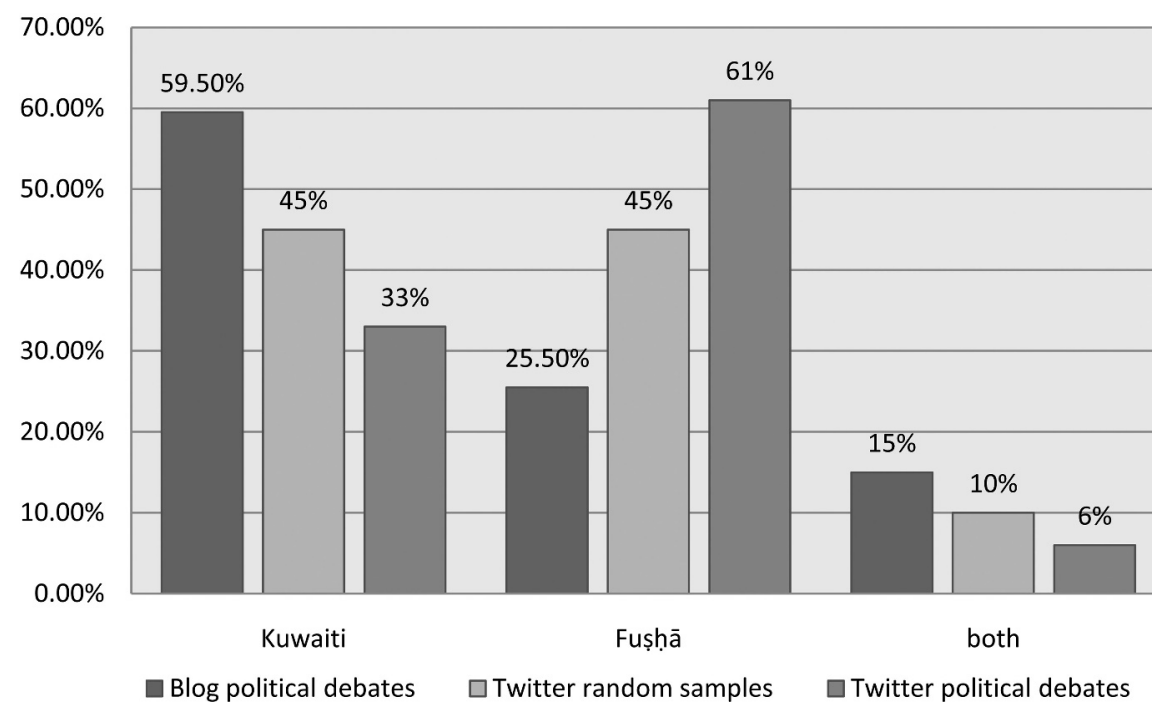

FIGURE 11.2 Distribution of all markers seen together, entries with markers, all samples

$@$ [User 6] (quoting/retweeting another user): You will not grow without feeling pain, you will not learn without making mistakes, and you will not succeed without failure, this is life.

“@[User 7]”, October 23rd 2014

However, this tendency was not as clear cut as within the political debates, and there were many examples of users preferring the KA variants as well, as in the following examples:

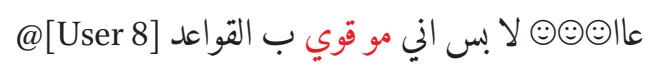

Aaa, no it's just that I am not that good in grammar @[User 8]

“@[User 9]” on September 22nd 2014

$$
\text { مدري ليش أحس فيك ... يا قطعة من قلبي }
$$

I don't know why I feel you ... (O/you) piece of my heart

“@[User 10]" on May 13th 2014

The results are remarkably similar when all markers are seen together, as shown in figure 11.2.

The samples from the blog quite clearly tend towards KA, the samples from the political debates quite clearly tend towards SA, and the random Twit- 
ter samples are found in the middle, with distribution being perfectly equal between KA and SA. That being said, there were exceptions in all samples. On several occasions, participants in the Twitter debates seemingly preferred KA, and participants in the blog debates SA:

$$
\text { اللي بيبيروح يروح .. واللي مايبي كيفه! ولايكثر \#سأخرج_للإرادة \#لن_أخرج_للإرادة }
$$

Those who wish to go should go ... and those who don't want to go should not! Don't overdo it

“@[User 11]", on August 26th 2012

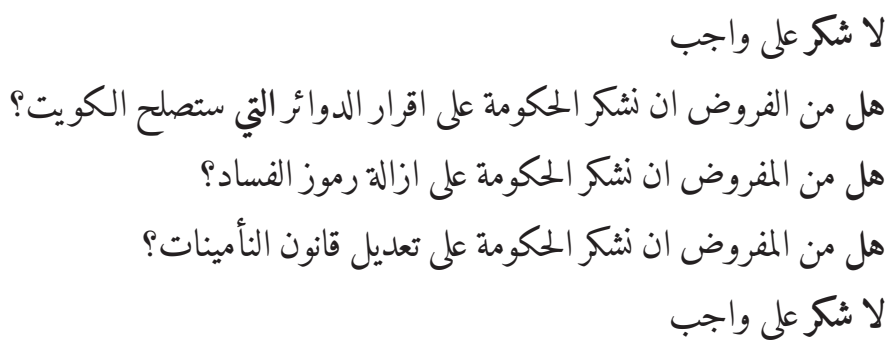

No thanks needed (to those who fulfill their duty). Is it necessary that we thank the Government for the decision on the [electoral] districts that will reform Kuwait? Is it necessary that we thank the Government for removing the symbols of corruption (the corrupted)? Is it necessary that we thank the Government for amending the law on social security? No thanks needed (to those who fulfill their duty).

"[User 12]", blog, on July 25th 2006

Whereas the comments written on the blog on a few occasions combined KA and SA, this was seldom found in the random Twitter samples, and almost never took place during the political debates on Twitter. The sA feature most often combined with the preferred KA in the comments written on the blogs was negations, although this hardly can be identified as a clear pattern:

$$
\begin{aligned}
& \text { (....) أكرر أنا لا أحب المظاهرات و هالسوالف } \\
& \text { بس عشان ديرتي أسوي كل شي }
\end{aligned}
$$

I repeat that I don't like demonstrations and these kinds of things, but for my homeland I do anything

"[User 13]", blog, May 3rd 2006 
On at least one occasion, the mixing seems to have taken place as a consequence of the use of a fixed expression:

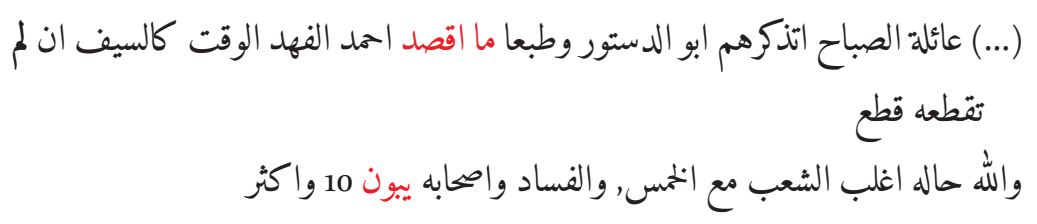

(...) I remind the Șabāh family of the father of the constitution, ${ }^{22}$ and of course I don't mean Ahmad al-Fahd, time is like a sword if you don't cut it, it will cut you, and what a situation, the majority of the people supports 5 [electoral districts], and the corrupted ones [lit: corruption and its masters] want ten or more

“[User 14]", blog, July 24th 2006

Similarly, in the very few instances KA was combined with the preferred sA variety in the political debates on Twitter, these were most often negations, although these cases also can be ambiguous, as in the following example:

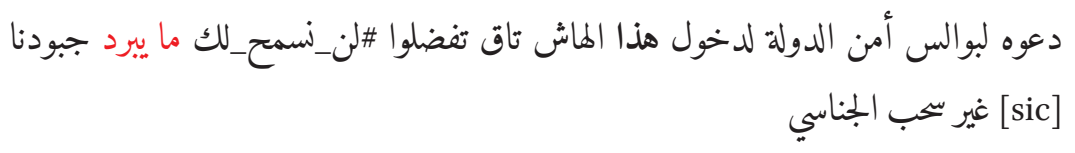

A call to the police of the national security to enter this hashtag, see what is written (hashtag), it won't cool off our efforts until [their] citizenship is revoked

“@[User 15]", October 15th 2012

However, even if negation is the feature that most often appear in general, there is hardly any basis to claim that negations is the feature that most often is mixed, also when the writer has a clear preference for either KA or SA. Within the random Twitter samples, there is no clear pattern to identify. When KA and SA features are combined, these include everything from negations to

22 The term "the father of the constitution" is a reference to former Amir Shaikh 'Abdallāh alSālim (ruler 1950-1965), who presided over Kuwait's transition to an independent country and the introduction of the constitution and the parliamentary system. By many Kuwaitis, in particular those in favor of reform, he is seen as the father of the modern state and an example of a just ruler. 
adverbs to interrogatives. Thus, this material does not suggest that there are any particular KA features that are kept also by those writing SA, nor the other way around.

The language used on the blog seems less formal than that of the political debates. The random samples constitute a middle ground, which may not be surprising: the tweets included in this sample may serve any purpose at all, they may have been written within many different contexts, with many different intended or expected audiences. This observation is further strengthened when we look at the languages used in the different samples, and the script with which the entries were written. A review of all tweets and comments in all the samples show that Arabic written in Arabic script is the preferred alternative in all three samples, but to varying degrees: while $100 \%$ of the tweets in the political debates were written in this manner, the corresponding figures for the blog debates and the random sample are $76 \%$ and $80,5 \%$, respectively. The second most preferred alternative in the latter two was English (constituting $11 \%$ and $13,5 \%$, respectively), followed by a combination of Arabic in Arabic script and English (5,5\% and 2,5\%) and Arabic written in Latin letters $(3 \%$ and $1 \%)$.

Thus, even though protagonists in the blog debates in 2006 might have faced technical difficulties in terms of writing Arabic with Arabic script, Arabeasy was almost never used. Rather, those not writing using Arabic script preferred English, or a combination of Arabic and English. The use of English is in itself interesting, as the debates mostly were conducted in Arabic. As follows, in order to participate one needed to understand Arabic (including KA), but some still chose to write their response in English, and seemingly assumed that everyone else would understand them:

Dear friends, I think what is going on here is very healthy. Everyone should be able to vent out what they are thinking about the picture.

"[User 16]", blog, July 24th 2006

OK I've been reading all the comments and I just can't keep silent. People PLEASE look OUTSIDE THE BOX!

"[User 17]", blog, July 24th 2006

The latter user above went on to mix Arabic in Arabic script and English for the remainder of the post. The passages in Arabic and English were different, what Sebba refers to as complementarity (Sebba 2012:15), which requires the reader to understand both languages in order to grasp the entire post. The use of English should be seen in connection with wide distribution of education in Kuwait, 
and the fact that many liberals, including the authors of the blog in question, have studied abroad (Nordenson 2010).

The political debates on Twitter were conducted in Arabic using Arabic script. This is hardly indicative of the participants not being able to read and write English, and groups and activists involved in the oppositional campaigns sometimes did write in English, particularly when they sought international attention towards their struggle. Rather, it seems the commonly accepted norm was that debates on domestic Kuwaiti issues were held in Arabic, written in Arabic script. As for the random sample, we see that Arabic written with Latin letters is almost nonexistent also in these entries. English, however, is used by quite a few, and $2 \%$ of the tweets were written in other languages than those listed here. This should not be surprising, as these were harvested solely based on geographical location. The majority of people living in Kuwait are not Kuwaiti citizens, and that foreigners chose to write in English or any other native language is hardly unexpected. In all, Arabic written in Latin letters is not a dominant feature of the online writings studied here; not in 2006 when some technical difficulties still existed, and not today. For those not writing in Arabic script, English is the preferred alternative. The question then, both with regard to the language and script used as well as the other findings presented here, would be what these results tell us, and how they can be explained.

\section{Dominant Features and Possible Explanations}

First of all, the findings support the point raised by Androutsopoulos (Androutsopoulos 2006:420-421) that there is no particular online language, not for the internet as such nor for any particular platform. There is a marked difference between the language employed in 2006 and in 2012, and there is also a difference between the political debates on Twitter and the random samples. As all entries were mediated online, this in itself is not a decisive factor. The topic of discussion, the participants, and the offline and online contexts seem to be of more importance. This does not mean that the technology involved is irrelevant. The 140 character limit set by Twitter is a constraint, although applications such as Twitlonger offer the possibility of publishing longer messages. Moreover, the instantaneous nature of online chat services does not encourage the user to spend time considering his or her grammar.

The results show that the local vernacular is used in writing online in Kuwait, supporting the agreement within the field that computer mediated communication has caused an increase in the use of written colloquial Arabic (Allmann 2009, Palfreyman and Khalil 2003, Ramsay 2012, Warschauer, Said and Zohry 
2002). This development is worrying to some proponents of SA, as the spread of colloquial varieties is seen to damage the written Arabic language (Mejdell 2008:115). However, the widespread use of written local dialects online does not in itself necessarily indicate a shift in language preferences. While online written communication may replace traditional letters, by and large it represents something new, and a massive expansion of written communication. Unlike letters, much of this communication takes place in public, on platforms such as Facebook, Twitter, and YouTube. Thus, the local varieties may just as well have filled a vacancy as they have replaced sA, and the use is a lot more visible than the use of local varieties may have been in the past.

Within the random samples, the distribution of KA and SA features is perfectly equal. Between the debates on the blog and on Twitter, there is a marked difference, and the tendency seems to be quite clear. One possible explanation for this would be the protagonists. The oppositional campaign in Kuwait over the past few years have been led by tribal and Islamist activists, as well as tribal and Islamist politicians, whereas the 2006 Orange Movement was dominated by liberal hadar. ${ }^{23}$ This may help explain the differences in the language employed. In a 2011 study of spoken Arabic in Kuwait, al-Qenaie found that hadar-speakers were less formal than badū-speakers (Al-Qenaie 2011:255). Given that previous studies have suggested that the instantaneous nature of СмC resemble that of spoken language (Allmann 2009, Palfreyman and Khalil 2003), similarities between written language online and spoken language offline may not be surprising. On the other hand, if this indeed is the most important factor, then we would expect to see a difference between the tweets using the hashtag in favor of participating in a demonstration - the view held by the opposition - and the tweets using the competing hashtag - the view held by those supporting the regime. However, I found no clear difference between the two.

Al-Qenaie also notes that the subject of discussion and the situation within which a discussion takes place is important in terms of the presence of KA or SA features of speech. Political discussions, in his analysis, are quite close to SA, with relatively few instances of colloquial features (Al-Qenaie 2011:254). Again, this may be of interest in order to explain the differences observed here. The 2006 debates on the blog were not only concerned with the issue at hand reform of the electoral districts - but also with how the movement should con-

23 That being said, there are many examples that indicate that while each movement may have been dominated by protagonists from different groups in society, individuals from all parts of Kuwaiti society took part. 
duct their work, that is, strategic discussion among those taking part. The 2012 debates on Twitter, on the other hand, were of a somewhat different nature: whether or not one should participate in a demonstration and thus support the opposition, and how to react to the speech given by a prominent oppositional politician. There were also strategic debates among the opposition that took place on Twitter, but these had markedly fewer participants. ${ }^{24}$ This, I believe, is linked to a very important difference between the 2006 and 2012 debates, namely the space in which they took place, and by extension, the intended and expected audience.

Internet usage was very different in Kuwait in 2006 than in 2012. As we have seen above, more than twice as many people use the internet in Kuwait today as compared 2006. Thus, even in an ideal scenario where a very high number of the total internet-users in the country visited the blog in question, those engaging in debates back then wrote for less people than those taking part in 2012. Moreover, online platforms were not an established tool for political activists in 2006, and they were not an established arena for political debates - they were introduced as such by the Orange Movement. Mark Lynch claims that "prior to 2006, most observers had seen the Kuwaiti blogosphere as relatively disengaged from politics and marginal to the public realm" (Lynch 2007:15). This stands in sharp contrast to the status of Twitter as an arena for debate today. According to al-Arabiyya, the Kuwaiti opposition view Twitter as the most important arena. ${ }^{25}$ Ahead of the July 2013 elections, hopeful candidates spent up to Us $\$ 35000$ to hire help in communicating on the platform, as it was seen as "a favorite platform to promote political campaigns". ${ }^{26}$ Importantly, these debates are taken very seriously by the regime, as evidenced by the harsh sentencing of some participants.

The nature of the debates was also different. Although the 2006 bloggers clearly sought to reach as wide an audience as possible with their message, the discussions predominantly took place between participants in the cam-

24 For instance, on January 3rd 2013, an initiative known as Karāmat Wațan (Dignity of a nation) that was formed to pressure the Emir to revoke some controversial changes to the electoral law, asked for Twitter users to provide suggestions for their next demonstration under the hashtag قطراحات_ كرامة_وطن5.|However, only 200 tweets were written using the assigned hashtag.

25 Al-Arabiyya, September 3rd 2012, "المعارضة تتسلح بدتويتر "لمواجهة الحكومة بالكويت. URL: http://www.alarabiya.net/articles/2012/o9/03/235804.html. Accessed: November 17, 2015.

26 Al-Arabiyya English, June 25th 2013, "Tweet politics: Kuwait election hopefuls embrace social media". URL: http://english.alarabiya.net/en/media/2013/o6/25/Kuwait-parliament -candidates-campaign-using-social-media.html. Accessed: November 17, 2015. 
paign. The blog often referred to a perceived "we", meaning those participating, fighting a righteous struggle against "them", meaning those who disagreed (Nordenson 2010:57). In other words, they were concerned with the unity of the group, and with building a strong community. This was confirmed by one key blogger, who argued that while they all were strangers prior to the campaign, they became "close cyber-friends" (Ibid., p. 58). While clearly important in order to build a strong movement, it also has implications for the tone and the language used during the discussions. Given the modest use of internet in Kuwait at the time, it also seems likely that the participants in the campaign were quite similar in terms of age and social background. In contrast, those participating in the 2012 debates were, in theory, speaking to leading politicians and members of the royal family, and were most of all concerned with expressing their view. Although the 2006 debates were published in public, they were of a more private character than those of 2012.

As a consequence, activists in 2006 primarily addressed their fellow campaigners. They often did so directly using the online user-names of others, and the tone by and large is amicable and informal; they were all part of the same group, they shared the same goals, and they often discussed how to best achieve these goals. A formal tone would hardly have been productive under these circumstances. The 2012 debates were different in this regard, and there is also a difference in the platforms used. In a debate in the comments field of a blog, all comments are gathered in one place, and it is easy to see who takes part and who does not. On Twitter, every user will see all tweets of those they follow in real time on their feed. Alternatively, they may follow a particular hashtag, which those participating in the debates most likely did. Then, one will also see all tweets using this hashtag in real time on one's feed. As some of these debates generated up to 10 ooo tweets, nobody would read them all. If one user wishes to address another user directly, s/he may do so by including his/her username in the message, but this was hardly ever done in the debates studied.

These differences in practice, or modes of discussion, between the blog debates and the Twitter debates affect the nature of the writings. As discussed above, many observers have argued that online writings could be quite similar to speech, particularly on certain platforms such as chat clients. Conversations online can be interactive, synchronous and sequential, features that Mark Sebba argues are crucial for conversational code-switching (Sebba 2012:6). The instantaneous nature of such discourse would also affect the time available to plan and produce a response for those taking part. As pointed out by Mejdell, a lack of such planning may affect the style of the speech in question (Mejdell 2006:381). This is quite different from written discourse, as observed by Eid: "Whereas spoken discourse is produced instantly in response to stimulus, lin- 
guistic or otherwise, written discourse is not. It is typically edited by the author, and possibly others as well, and has the advantage of hindsight and time" (Eid 2002:205). The differences observed by Eid are highly relevant to the differences in practice described above: those taking part on the blog discussed instantaneously and sequentially with each other on the same site, with all entries being visible for all participants. Those taking part on Twitter published an utterance in a debate without knowing who they would reach, whether they would receive a response, and their message was not part of a sequential debate. Thus, practice and context should be seen as important features in order to differentiate between utterances that correlate to what traditionally (offline) would be termed "written discourse" and "spoken discourse." The distinction between the terms remains relevant even though the discussion in both cases was in fact written, although other terms may perhaps be used to avoid confusion, such as "speech-like written" and "written". Moreover, these differences in practice may help explain the differences observed between the blog debates and the Twitter debates. Finally, while important in themselves, these differences in practice are closely related to whom the protagonists believe they address. Although most participants on Twitter would have no idea if their tweets were actually read, and if so, by whom, they did know that important persons of authority might take part in the same debate, and in theory might read - and even respond to - their own writings.

Thus, the intended, expected, and possible audiences would be different between the two cases. In this regard, Alan Bell's framework on audience design may explain the differences observed. As argued by Bell, "[s]peakers design their style for their audience" (Bell 1984:159). Bell further recognizes that other factors also are at play, such as topic and setting, but that these are of relevance due to the implicit connotations on audience they carry with them: "[w]e must continue to treat topic and setting as variables which have independent effects on style, while remembering that at base they are derivative" (Ibid., p. 182). Interestingly, Bell argues that "referee design is shown to be especially powerful in mass communication". Referees are "third persons not physically present at an interaction, but possessing such salience for a speaker that they influence speech even in their absence" (Ibid., p. 186). Referee design is divided into ingroup and outgroup referee design. Ingroup "sees a speaker talking to members of an outgroup, and reacting with a shift towards the style of the speaker's own (absent) ingroup". Outgroup, on the other hand, means that "speakers lay claim to a speech and identity which are not their own but which hold prestige for them on some dimension" (Ibid., pp. 187-188). In terms of its relevance for mass communication, Bell turns to the mass media and argues that its audience is unspecific - a "perceived class of persons" (Ibid.:192). 
The protagonists in the political debates on Twitter do not know if they are read by the political elite, but they might be, and accordingly they employ the language they perceive as fitting for the occasion. They do not necessarily design their messages for those that they know will read them, but for those that may or may not be part of the general discussion. The audience, both the expected and the possible, was quite different for those taking part in 2006, and as such, audience design, and in particular referee design, constitutes a compelling explanation for the differences observed.

To the extent that the tendencies identified are representative of online language usage in Kuwait, they underline a key aspect observed also in previous studies: language usage online is not accidental. The protagonists are pragmatic, and use their language resources for different purposes and in different settings. While the average Twitter user in Kuwait may write more or less formally, sA features are preferred when discussing politics. Hence, while it is true that more colloquial Arabic now is used in writing, it is not given that this will diffuse the difference between spoken and written Arabic, as it may occur in addition to and not to the detriment of written SA. Online communication, as we have seen, may be many different things, which may call for different linguistic styles, depending on factors such as audience, subject, setting, and established practice. In fact, online written communication could bolster the use of written SA, as people write more (in a quantitative sense), and use different styles for different purposes, thus becoming more conscious of their linguistic resources. Online communication does, however, offer empowerment in the sense that people are able to write as they like, unhindered by traditional, hegemonic forces in society. Thus, online platforms may be a vehicle to challenge existing perceptions of language usage, but they do not drive such change in and of themselves.

\section{Conclusion}

I have described some characteristics of the language used online by activists in Kuwait in two particular cases and identified differences between these. Possible explanations have also been provided, although some questions are left unexplored. It is the hope of this author that this study may serve as a starting point for other investigations into language use online - in Kuwait and elsewhere - and that the explanations suggested may be tested through further, empirical evidence.

The material suggests a marked difference between the blog debates in 2006 and the Twitter debates in 2012, with the former tending towards KA, and the 
latter tending towards SA. Various possible explanations were discussed, but differences in the intended and the possible audiences seem to be the most compelling. This, in turn, includes - albeit implicitly - differences in subject and setting. Whereas the blog debates in 2006 took place in a semi-private setting and mostly involved people who were familiar with each other and who shared the same goal, the later Twitter debates were part of the public, political debate of the country. If this holds true, it seems an informal tone employing many KA features is considered appropriate and productive when talking to fellow activists, whereas a more formal tone featuring many sA markers is considered appropriate for a public political discourse. This is also in line with the findings presented by al-Qenaie on oral language usage in the country, and may suggest that users consciously and pragmatically adjust their style in accordance with topic, setting, and the audience. It would be interesting to conduct similar studies in other countries. If indeed a certain style is deemed appropriate for public political discussions in Kuwait, this may not be so in other contexts. Furthermore, if users online do adjust their languages, studies on the use of different styles may prove informative as to how various topics, settings, and audiences are perceived in different contexts.

Hopefully, this study may also contribute to the development of methodological designs suitable for such studies, as called for by Ramsay. While previous studies usually have been concerned with particular individuals or small groups of informants, open platforms such as Twitter, Facebook, and Blogs allow us to get the "bigger picture" in the sense of harvesting large samples based on location, subject, and the like. This material can then be analyzed in a number of ways, in this case through coding of KA markers, SA markers, or a combination of the two, but it may of course be used to investigate other features as well. As the design is well suited to identify interesting phenomena and changes on a macro-level, it would be ideal to combine with more detailed studies on a micro-level in order to provide more comprehensive conclusions.

Finally, the study has contributed to the "demythologization" of computer mediated communication called for by Androutsopoulos. There is no evidence in the material studied that suggests that technology is decisive for the language choices made online, or that some distinct 'internet language' exists. Conclusions and theories as to online language usage and the development of Arabic due to its usage online should be informed by topic, setting, audience, practice, and the protagonists involved - not the technology used. 


\section{References}

Aboelezz, Mariam. 2009. "Latinised Arabic and Connections to Bilingual Ability." in The Lancaster University Postgraduate Conference in Linguistics and Language Teaching. Al-Nakib, Farah. 2014. "Revisiting Ḥaḍar and Badū in Kuwait: Citizenship, Housing, and the Construction of a Dichotomy." International Journal of Middle East Studies 46(01):5-30.

Al-Qenaie, Shamlan. 2011. "Kuwaiti Arabic: A Socio-Phonological Perspective.” Durham University.

Allmann, Kira. 2009. "Arabic Language Use Online: Social, Political, and Technological Dimensions of Multilingual Internet Communication." The Monitor (Winter 2009):61-76.

Androutsopoulos, Jannis. 20o6. "Introduction: Sociolinguistics and Computer-Mediated Communication." Journal of Sociolinguistics 10(4):419-438.

Bell, Allan. 1984. "Language Style as Audience Design." Language in society 13(02):145204.

Eid, Mushira. 2002. "Language Is a Choice: Variation in Egyptian Women's Written Discourse1." Pp. 203-233 in Language Contact and Language Conflict in Arabic Variations on a Sociolinguistic Theme, edited by A. Rouchdy. New York: Routledge.

Ghabra, Shafeeq. 1997. "Kuwait and the Dynamics of Socio-Economic Change." The Middle East Journal 51(3):358-372.

Herb, Michael. 1999. All in the Family: Absolutism, Revolution, and Democracy in Middle Eastern Monarchies. New York: sunY Press.

Holes, Clive. 1984. Colloquial Arabic of the Gulf and Saudi Arabia. London \& New York: Routledge \& Kegan Paul.

Holes, Clive. 1990. Gulf Arabic. London \& New York: Routledge.

Holes, Clive. 2011. "Kuwaiti Arabic." in Brill Online, edited by Lutz Edzard and R. de Jong: Brill.

Lynch, Marc. 2007. "Blogging the New Arab Public." Arab Media \& Society 1(1).

Mejdell, Gunvor. 2006. Mixed Styles in Spoken Arabic in Egypt: Somewhere between Order and Chaos. Leiden \& Boston: Brill.

Mejdell, Gunvor. 2008. "What Is Happening to Lughatunā L-Gamila? Recent Media Representations and Social Practice in Egypt." Journal of Arabic and Islamic Studies 8:108-124.

Mocanu, Delia, Andrea Baronchelli, Nicola Perra, Bruno Gonçalves, Qian Zhang and Alessandro Vespignani. 2013. "The Twitter of Babel: Mapping World Languages through Microblogging Platforms." PloS one 8(4):e61981.

Mourtada, Racha, Fadi Salem and Sarah Shaer. 2014. "The Arab World Online 2014: Trends in Internet and Mobile Usage in the Arab Region." Dubai, UAE: The Mohammed bin Rashid School of Government. 
Mourtada, Racha, Fadi Salem and Sarah Shaer. 2014. "Citizen Engagement and Public Services in the Arab World: The Potential of Social Media." Vol. 6. Arab Social Media Report. Dubai, UAE: The Mohammed bin Rashid School of Government.

Nordenson, Jon. 2010. We Want Five! - Kuwait, the Internet, and the Public Sphere. Saarbrücken: LAP Lambert Academic Publishing.

Orgad, Shani. 2008. "How Can Researchers Make Sense of the Issues Involved in Collecting and Interpreting Online and Offline Data." Pp. 33-53 in Internet Inquiry Concersations About Method, edited by A. N. Markham and N. K. Baym. Thousand Oaks: Sage.

Palfreyman, D. and M. Khalil. 2003. “'A Funky Language for Teenz to Use:' Representing Gulf Arabic in Instant Messaging." Journal of Computer-Mediated Communication $9(1): 1-33$.

Peel, Richard. 2004. "The Internet and Language Use: A Case Study in the United Arab Emirates." International Journal on Multicultural Societies 6(1):79-91.

Qafisheh, Hamdi A. 1997. Ntc's Gulf Arabic-English Dictionary. Chicago: NTC Publishing Group.

Ramsay, Gail. 2012. "What Kind of Arabic and Why? Language in Egyptian Blogs." Orientalia Suecana 61: 49-87.

Salem, Paul. 2008. "Kuwait: Politics in a Participatory Emirate." Pp. 211-230 in Beyond the Facade - Political Reform in the Arab World, edited by M. Ottaway and J. ChoucairVizoso. Washington D.C.: Carnegie Endowment for International Peace.

Sebba, Mark. 2012. "Researching and Theorising Multilingual Texts." Pp. 1-27 in Language Mixing and Code-Switching in Writing, edited by M. Sebba, S. Mahootian and C. Jonsson. New York: Routledge.

Warschauer, Mark, Ghada R. El Said and Ayman G. Zohry. 2002. "Language Choice Online: Globalization and Identity in Egypt." Journal of Computer-Mediated Communication $7(4): 1-24$. 